\title{
Inspiratory crackles and mechanical events of breathing
}

\author{
A. R. NATH and L. H. CAPEL \\ The London Chest Hospital, Bonner Road, London E2
}

\begin{abstract}
Nath, A. R. and Capel, L. H. (1974). Thorax, 29, 695-698. Inspiratory crackles and mechanical events of breathing. Forgacs (1967) has suggested that the timing of individual inspiratory crackles is determined by the elastic tension of the lung. This hypothesis was tested by recording the inspiratory crackles simultaneously with a recording of transpulmonary pressure, inspired volume, and inspiratory flow rate. The timing of an individual crackle was found to be closely associated with a particular transpulmonary pressure.
\end{abstract}

Forgacs $(1967,1969)$ has suggested that inspiratory crackles coincide with the sudden opening of airways in deflated territories of the lung. He thought that the sequence and timing of each inspiratory crackle are determined by the elastic tension required to open individual airways.

As inspiration progresses radial traction on the airway wall increases. When a critical transmural pressure gradient is reached the airway abruptly opens, and rapid equalization of pressure between the upstream and downstream section of the airway follows. A crackle is generated during this brief period of pressure equalization when the gas is set in transient oscillation. If an individual crackle is generated by the opening of a single airway its timing should be linked to the elastic lung tension required to open the airway which in turn is related to lung volume and transpulmonary pressure.

This hypothesis was tested by recording inspiratory crackles simultaneously with the transpulmonary pressure and the inspired volume.

\section{PATIENTS}

Six patients who showed a repetitive pattern of inspiratory crackles were studied. All patients showed the clinical, radiological, and functional abnormalities of restrictive lung disorder. The clinical findings, spirometric data, and transfer factor measurements are shown in Table I.

\section{METHODS}

Inspiratory crackles were recorded using a crystal microphone mounted in an aluminium cup with a suction chamber which was attached to the posterior chest wall $5 \mathrm{~cm}$ above the costal margin. The output of the microphone was amplified and displayed on one channel of a UV recorder (SE Type 3006/DL). The sound amplifier incorporated a variable high pass filter with a cut-off at $600 \mathrm{~Hz}$.

The inspiratory flow rate was simultaneously recorded at the mouth with a Fleisch pneumotachograph coupled to a differential pressure manometer (Mercury Electronics, Type M6) and the output displayed on a second channel of the recorder. The flow rate signal at zero was superimposed on the sound baseline. Thus the start and the finish of inspiration were indicated by the flow signal as it crossed the sound signal baseline (Fig. 1). The inspired volume was recorded on the third channel by electrical integration of the flow signal.

The transpulmonary pressure change was measured from the beginning of each inspiration on the fourth channel with an oesophageal balloon sealed over a polyethylene catheter connected to a differential pressure transducer (Mercury Electronics, Type M6). The tip of the balloon was $45 \mathrm{~cm}$ from the mouth. The technique of measurement was as described by MilicEmili, Mead, Turner, and Glauser (1964). The $90 \%$ response time of the catheter manometer system related to an instantaneous sound signal was $0.06 \mathrm{sec}$.

The recordings were made with the subject sitting upright performing slow vital capacity breaths. After a few breaths the subject was instructed to vary the depth of breathing from about the same end expiratory level.

Inspiratory crackles often show a repetitive pattern from cycle to cycle (Forgacs, 1967, 1969). A particular recurring crackle might therefore be identified by its relative loudness and timing in relation to other crackles when these repeat from breath to breath (Figs 1 and 2). From the sound record it was usually possible to identify at least one crackle by its intensity 
T A B L E I

CLINCAL AND PHYSIOLOGICAL DATA OF 6 PATIENTS WITH INSPIRATORY CRACKLES

\begin{tabular}{|c|c|c|c|c|c|c|c|}
\hline $\begin{array}{l}\text { Patient } \\
\text { No. }\end{array}$ & $\begin{array}{l}\text { Age } \\
\text { (yr) }\end{array}$ & Sex & Diagnosis & $\begin{array}{c}\text { Forced Expiratory } \\
\text { Volume }(1 \mathrm{sec}) \\
\text { (litres) }\end{array}$ & $\begin{array}{l}\text { Vital Capacity } \\
\text { (litres) }\end{array}$ & $\mathrm{FEV}_{\frac{1}{\%}} / \mathrm{VC}$ & $\begin{array}{l}\text { Transfer Factor } \\
(\mathrm{ml} / \mathrm{min} / \mathrm{mmHg})\end{array}$ \\
\hline 1 & 52 & $\mathbf{M}$ & Asbestosis & $2 \cdot 90$ & $\begin{array}{l}3 \cdot 85 \\
(97)\end{array}$ & & $\begin{array}{c}21 \\
(70)\end{array}$ \\
\hline 2 & 53 & $\mathbf{M}$ & Asbestosis & 1.95 & 2.95 & 66 & $\begin{array}{c}17 \\
(68)\end{array}$ \\
\hline 3 & 50 & $\mathbf{M}$ & $\begin{array}{l}\text { Systemic lupus } \\
\text { erythematosus }\end{array}$ & $2 \cdot 70$ & $\begin{array}{l}3.60 \\
(83)\end{array}$ & 75 & 10 \\
\hline 4 & 59 & $\mathbf{M}$ & Scleroderma & $2 \cdot 60$ & $\begin{array}{l}3.90 \\
(100)\end{array}$ & 67 & 16 \\
\hline 5 & 53 & $\mathbf{M}$ & Fibrosing & $2 \cdot 67$ & $3 \cdot 80$ & 70 & 13 \\
\hline 6 & 74 & $\mathbf{M}$ & $\begin{array}{c}\text { Fibrosing } \\
\text { alveolitis }\end{array}$ & $1 \cdot 80$ & $\begin{array}{l}2 \cdot 10 \\
(67)\end{array}$ & 86 & $\begin{array}{c}13 \\
13 \\
(68)\end{array}$ \\
\hline
\end{tabular}

Figures in parentheses represent percent of predicted value.

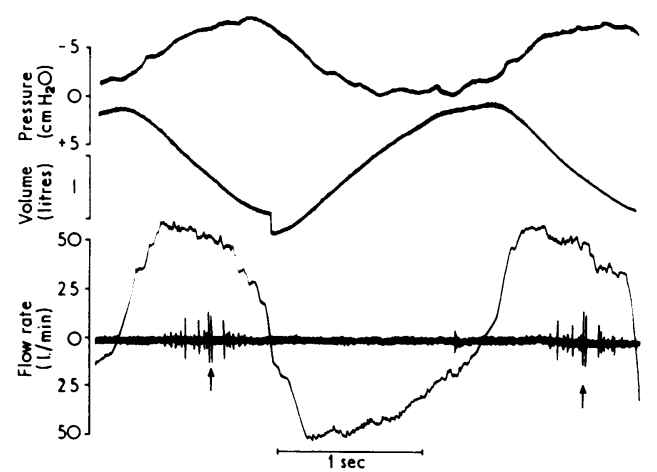

FIG. 1. Simultaneous recording of inspiratory crackles, airflow rate, lung volume, and transpulmonary pressure in a patient with scleroderma. A pair of repetitive crackles in two breaths may be noted. This pattern was repeated in nine successive breaths. The measurements were made at the moment of occurrence of the second of the paired crackle (the index crackle, arrowed). The base line of the sound channel is also the zero flow line of the flow rate signal, hence the flow rate signal indicates the start and end of inspiration as it passes through the base line.

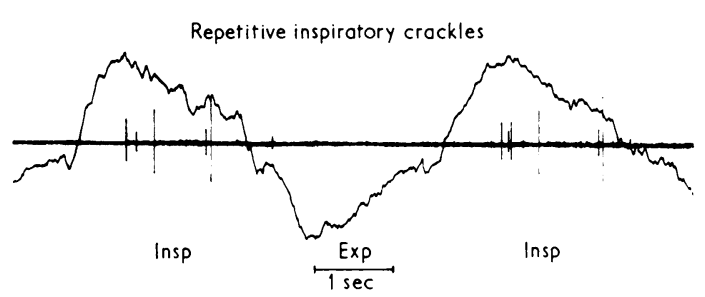

FIG. 2. Simultaneous recording of inspiratory crackles and air flow rate. $A$ repetitive pattern of crackles in the two breaths is seen.

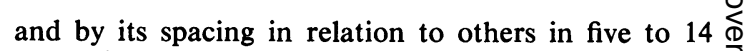
successive respiratory cycles. When an index crackle $\bar{\sigma}$ was so identified, the time interval from the start of $\mathbb{\Phi}$ inspiration to the index crackle, the inspired volume, and the instantaneous flow rate at the moment of $\vec{\theta}$ the index crackle in consecutive breaths was $\perp$ measured. In four of the six patients the transpulmonary pressure change from the start of inspiration to the index crackle was also measured. In two patients ( 1 and 3 ) the whole experiment was repeated, making a total of eight experiments in the six patients.

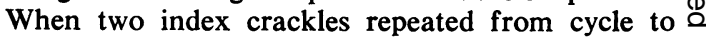
cycle, the volume separating the two index crackles $\overrightarrow{\overrightarrow{0}}$ and the total inspired volume were measured. The 3 index crackles were always identified as described above before the measurements were made.

\section{RESULTS}

The results of one experiment in a patient with pulmonary asbestosis are illustrated in Fig. 3 as an example. The length of the horizontal lines in the columns from left to right represents the inspiratory time, the inspiratory flow rate, the 은 inspired volume and the transpulmonary pressure. The short vertical line transecting the horizontal line represents the index crackle repeating $N$ through eight breaths. The inspired volume at the moment of index crackle is seen to remain within $N$ a narrow range (mean $660 \mathrm{ml}$; range $600-695 \mathrm{ml}$; స్ SD $36 \mathrm{ml}$ ) although the total inspired volume $\sigma$ varied from 630 to $1,290 \mathrm{ml}$. Similarly, the 0 transpulmonary pressure at the moment of $\overparen{D}$ index crackle showed only small variations $\stackrel{?}{+}$ (mean 12.8 $\mathrm{cmH}_{2} \mathrm{O}$; range 12.8-14.8 $\mathrm{cmH}_{2} \mathrm{O}$; SD $0.7 \mathrm{cmH}_{2} \mathrm{O}$ ). In contrast, larger variations were seen in the time interval from the start of $\stackrel{D}{\Omega}$ inspiration to the crackle (mean $0.99 \mathrm{sec}$; range $\mathbb{Q}$ $0.78-1.42 \mathrm{sec}$; SD $0.24 \mathrm{sec}$ ), and the instantaneous 

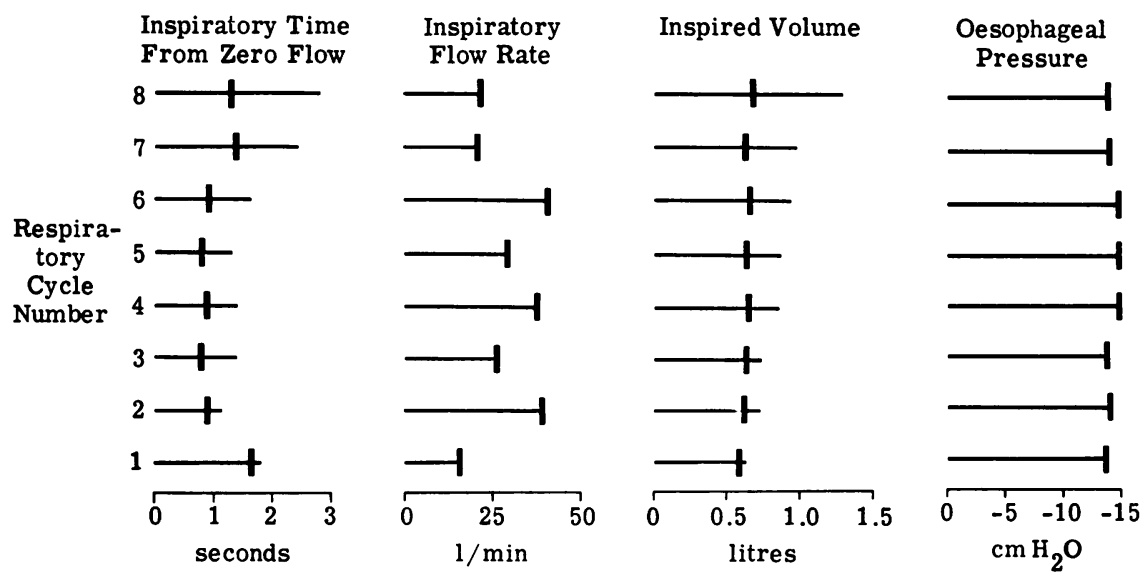

FIG. 3. Diagrammatic representation of results of a single experiment recording eight breaths. The length of horizontal line represents from left to right the inspiratory time, the inspiratory flow rate, the inspired volume, and the transpulmonary pressure in the units given. The short vertical line represents the occurrence of a particular index crackle repeating through eight breaths. It can be seen (last two columns) that the crackle occurred at a similar inspired volume and transpulmonary (oesophageal) pressure although the total inspired volume was varied in the eight breaths. The occurrence of this crackle, however, is not closely related to the inspiratory time and inspiratory flow rate (first two columns).

inspiratory flow rate (mean $29 \mathrm{l} / \mathrm{min}$; range 14-40 $1 / \mathrm{min}$; SD $9 \cdot 11 / \mathrm{min}$ ) at the moment of crackle. Thus the occurrence of the index crackle in this experiment was more closely related to the transpulmonary pressure and the inspired volume than to the time interval or the instantaneous flow rate.

Table II shows the coefficient of variation $\left(\frac{\mathrm{SD}}{\text { mean }} \times 100\right)$ for the inspiratory time, the instantaneous inspiratory flow rate, the inspired volume and the transpulmonary pressure at the moment of the index crackle in the eight experiments, and the mean values of grouped observa- tions. In all experiments the least variation was found in the inspired volume and the transpulmonary pressure while the largest variation was seen in the inspiratory time and the inspiratory flow rate. The difference between the lower mean values for the variations in the transpulmonary pressure and the inspired volume and the higher mean values for the variations in the inspiratory time and the inspiratory flow rate are statistically significant $(P<0.01)$.

In two patients the volume change between two index crackles occurring together in each inspiratory phase for a series of cycles was measured (Table III). In one patient the volume change

T A B L E I I

COEFFICIENT OF VARIATION $\left(\frac{\text { SD }}{\text { MEAN }} \times 100\right)$ OF INSPIRATORY,TIME, INSPIRATORY [FLOW RATE, INSPIRED VOLUME, AND TRANSPULMONARY PRESSURE AT INDEX CRACKLE IN 8 EXPERIMENTS

\begin{tabular}{|c|c|c|c|c|}
\hline Experiment No. & $\begin{array}{c}\text { Inspiratory Time } \\
\%\end{array}$ & $\begin{array}{l}\text { Inspiratory Flow Rate } \\
\%\end{array}$ & $\begin{array}{c}\text { Inspired Volume } \\
\%\end{array}$ & $\begin{array}{c}\text { Transpulmonary Pressure } \\
\%\end{array}$ \\
\hline $\begin{array}{l}1 \\
2 \\
3 \\
4 \\
5 \\
6 \\
7 \\
8\end{array}$ & $\begin{array}{r}24.2 \\
29.0 \\
9.4 \\
18.6 \\
15.4 \\
17.8 \\
20.4 \\
6.9\end{array}$ & $\begin{array}{r}31.0 \\
20.5 \\
9.5 \\
10.5 \\
16.0 \\
29.4 \\
9.7 \\
13.5\end{array}$ & $\begin{array}{l}5.5 \\
4.4 \\
2.4 \\
8.9 \\
2.3 \\
3.1 \\
8 \cdot 8 \\
3.3\end{array}$ & $\begin{array}{l}\frac{5.5}{} \\
\overline{4.6} \\
1.4 \\
\frac{6.5}{-}\end{array}$ \\
\hline $\begin{array}{l}\text { Mean } \\
\text { SD }\end{array}$ & $\begin{array}{r}17 \cdot 7 \\
7 \cdot 3\end{array}$ & $\begin{array}{r}17 \cdot 5 \\
8 \cdot 7\end{array}$ & $\begin{array}{l}4 \cdot 8 \\
2 \cdot 7\end{array}$ & $\begin{array}{l}4 \cdot 5 \\
2 \cdot 1\end{array}$ \\
\hline
\end{tabular}




\section{T A B L E I I I}

MEAN VOLUME CHANGE BETWEEN TWO INDEX CRACKLES RELATED TO TOTAL INSPIRED VOLUME IN CRACKLES RELATED TO TOTAL INSPIR

\begin{tabular}{c|c|c|c||c}
\hline $\begin{array}{c}\text { Patient } \\
\text { No. }\end{array}$ & $\begin{array}{c}\text { No. of } \\
\text { Breaths }\end{array}$ & $\begin{array}{c}\text { Mean Volume } \\
\text { Change between } \\
\text { Two Crackles } \\
\text { (range) }\end{array}$ & SD & $\begin{array}{c}\text { Mean Total } \\
\text { Inspired Volume } \\
\text { (range) }\end{array}$ \\
\hline 1 & 13 & $\begin{array}{c}250 \mathrm{ml} \\
(200-320) \\
190 \mathrm{ml} \\
(130-335)\end{array}$ & 58 & $\begin{array}{c}1,675 \mathrm{ml} \\
(1,200-2,100) \\
860-12 \\
(630-1,290)\end{array}$ \\
\hline
\end{tabular}

between the two crackles was measured in 13 successive breaths. The total inspired volume in each of 13 breaths varied from 1,200 to $2,100 \mathrm{ml}$. The mean volume change from the first to the second crackle was $250 \mathrm{ml}$, and the variation round this mean was only $36 \mathrm{ml}$ (1 SD). This variation is thus small when related to the total inspired volume. The corresponding mean volume change separating the two crackles in the second patient was $190 \mathrm{ml}$ and the variation around the mean was $58 \mathrm{ml}(1 \mathrm{SD})$ when the total inspired volume varied from 630 to $1,290 \mathrm{ml}$ in 10 successive breaths.

\section{DISCUSSION}

Forgacs' brilliant analysis of the generation of lung sounds was the starting point of this study. $\mathrm{He}$ observed that inspiratory crackles frequently show a recurrent pattern in consecutive respiratory cycles and suggested that the repetitive sequence of sounds implies that each crackle is related to the recurrence of specific pressure and volume changes from breath. He suggested further that an individual crackle is generated by the explosive opening of a closed airway in a deflated region of the lung, and that the opening of the airway is determined by the elastic pull on its wall and hence by the magnitude of lung inflation.

This hypothesis has been tested by simultaneous measurement of transpulmonary pressure and lung volume in four patients with repetitive inspiratory crackles. The transpulmonary pressure changes from the beginning of inspiration to the moment of a particular crackle have been found to vary little in inspirations of differing volumes.

It has been assumed that transpulmonary pres- $\frac{\bar{O}}{\sigma}$ sure reflects changes in lung recoil and that the $\frac{\bar{m}}{\bar{m}}$ flow-resistive component could be neglected. This $\overparen{\Phi}$ is a reasonable approximation in a study of patients without airways obstruction in whom the transpulmonary pressure has been recorded at low $\vec{\circ}$ inspiratory flow rates and in whom the variation $\vec{\overrightarrow{ }}$ of inspiratory flow rate from breath to breath in each experiment was small (Table IV). The $\overrightarrow{\vec{x}}$ inspired volume at the moment of a particular crackle in eight experiments in six patients has also been found to remain within a narrow range 9 from breath to breath in each case. This remained $\delta$ a feature even when the total inspired volume was 0 varied in consecutive respiratory cycles (Fig. 3). When the occurrence of two index crackles was $z$ followed from breath to breath the change in lung volume from one crackle to another showed $\stackrel{\mathbb{\$}}{3}$ but small variation in relation to the total inspired ${ }_{\mathbb{\Phi}}$ volume.

These observations support Forgacs' hypothesis $\vec{\varphi}$ that an inspiratory crackle arises from the explo- + sive opening of a closed airway at a time when a critical transmural pressure develops as radial traction increases with lung inflation. This episode of opening of a closed airway could result from the development of a critical pressure gradient up $\frac{2}{\infty}$ and downstream of the point of closure or by $\vec{F}$ radial traction on the airway by the expanding lung. Either mechanism is consistent with the results of this study.

We should like to thank Mrs. L. M. Butcher for typing the script and Miss L. Pegus and Mr. K. Moorman for help with the illustrations.

\section{REFERENCES} Forgacs, P. (1967). Crackles and wheezes. Lancet, 2,

(1969). Lung sounds. British Journal of Diseaseso of the Chest $63,1$.

Milic-Emili, J., Mead, J., Turner, J. M., and Glauser, E. M. (1964). Improved technique for estimating pleural pressure from esophageal balloons. Jour- N nal of Applied Physiology, 19, 207.

Requests for reprints to: Dr. L. H. Capel, The N London Chest Hospital, Bonner Road, London E2.

T A B L E I V

MEAN INSTANTANEOUS INSPIRATORY FLOW RATE AT MOMENT OF INDEX CRACKLE

\begin{tabular}{|c|c|c|c|c|c|c|c|c|}
\hline & \multicolumn{8}{|c|}{ Experiment No. } \\
\hline & 1 & 2 & 3 & 4 & 5 & 6 & 7 & 8 \\
\hline $\begin{array}{l}\text { Mean inspiratory flow rate }(1 / \mathrm{min}) \\
\text { SD }\end{array}$ & $\begin{array}{l}29 \\
9 \cdot 1\end{array}$ & $\begin{array}{c}56 \\
11 \cdot 5\end{array}$ & $\begin{array}{c}31 \\
3.0\end{array}$ & $\begin{array}{l}43 \\
4 \cdot 5\end{array}$ & $\begin{array}{c}69 \\
10 \cdot 9\end{array}$ & $\begin{array}{l}31 \\
9 \cdot 1\end{array}$ & $\begin{array}{r}61 \\
5 \cdot 9\end{array}$ & $\begin{array}{l}43 \\
5 \cdot 8\end{array}$ \\
\hline
\end{tabular}

